\title{
O SERVILISMO TEM QUE MORRER: RESPOSTA A VLADIMIR SAFATLE
}

\author{
MURILO SEABRA $^{1}$ e LAURA TOLTON ${ }^{2}$
}

\begin{abstract}
RESUMO: Em fins de 2016, os professores Rafael Haddock-Lobo e Vladimir Safatle mantiveram um debate interessante, apesar de curto, sobre a situação da filosofia no Brasil. Publicados um tanto discretamente no site da Associação Nacional de Pós-Graduação em Filosofia (ANPOF), os seus artigos não receberam ainda a devida atenção. O que vamos fazer aqui é defender a posição de Haddock-Lobo contra as investidas de Safatle. A nossa argumentação mostrará que (a) a crítica safatliana não se sustenta (o que não impede que a posição de Haddock-Lobo possa ser criticada por outra via); (b) faz todo sentido colocar a pergunta pela filosofia brasileira nos termos propostos por Haddock-Lobo; (c) o verdadeiro problema da filosofia acadêmica brasileira, ao contrário do que sugere Safatle, não é um problema de campo (o que pode ser mostrado com os argumentos do próprio Safatle); (d) embora Safatle esteja certo em criticar o regime de filiações que caracteriza a filosofia acadêmica brasileira, ele perde de vista o tipo de filiação que realmente importa criticar; (e) finalmente, existe uma afinidade muito maior entre Safatle e Haddock-Lobo do que é possível discernir à primeira vista. Por motivos de espaço, preferimos pressupor uma familiaridade prévia com os artigos de Haddock-Lobo e Safatle (que podem ser facilmente acessado no site da ANPOF) e concentrar os nossos esforços na análise do debate que eles travaram.
\end{abstract}

PALAVRAS-CHAVE: filosofia brasileira; filosofia no Brasil; metafilosofia; Vladimir Safatle; Rafael Haddock-Lobo.

ABSTRACT: Toward the end of 2016, professors Rafael Haddock-Lobo and Vladimir Safatle held an interesting, albeit short debate on the situation of Brazilian philosophy. Published rather discretely on the website of the Brazilian National Association of Postgraduate Studies in Philosophy (ANPOF), their papers have not yet received the attention they deserve. Here we defend Haddock-Lobo's position against Safatle's criticisms. We will show that (a) Safatle's criticisms lack soundness (of course, one can still find an alternative path in order to criticize Haddock-Lobo); (b) it makes perfect to sense to raise the question concerning Brazilian philosophy in Haddock-Lobo's terms; (c) contrary to what Safatle suggests, the real problem with Brazilian academic philosophy is not an institutional matter related to the field (which can be shown with Safatle's own arguments); (d) although Safatle is right in criticizing the filiation regime that characterizes Brazilian academic philosophy, he loses sight of the type of filiation which should really be criticized; (e) finally, there is a much greater affinity between Safatle and Haddock-Lobo than one can gather in a quick glance. A limitation of space forces us to presuppose the reader's familiarity with Haddock-Lobo's and 
Safatle's papers (which can be easily accessed on the ANPOF website) and to focus our efforts solely on the analysis of their debate.

KEYWORDS: Brazilian philosophy; Philosophy in Brazil; metaphilosophy; Vladimir Safatle; Rafael Haddock-Lobo.

Em sua coluna da Folha de São Paulo publicada no dia 06 de novembro de 2015, Safatle criticou com precisão cirúrgica a ideia de que o governo Dilma era estatista e intervencionista. Um governo que "abriu a exploração do pré-sal para empresas estrangeiras, entregando $60 \%$ da maior reserva de petróleo da camada salina para quatro empresas estrangeiras" não podia ser coerentemente qualificado nem de uma coisa nem de outra (SAFATLE, 2015). Evidentemente, Safatle não criticou a entrega de $60 \%$ do pré-sal a "empresas estrangeiras" por achar que as elites brasileiras é que deveriam ser as exclusivas beneficiárias. Atribuir uma visão tão estreita e superficial a Safatle, como se o interesse dele fosse defender os interesses das elites brasileiras, seria pura e simplesmente um ato de má-fé. Mesmo que não entregar $60 \%$ do pré-sal a empresas estrangeiras significasse, na prática, entregá-lo às elites nacionais, seria distorcer completamente as suas palavras dizer que ele estava, no fundo, advogando em favor delas. Se Safatle pode ser visto como um defensor do nacionalismo econômico, não se trata, obviamente, de um nacionalismo cínico, grosseiro e raso que visa unicamente garantir os interesses das elites nacionais. Uma coisa é criticar políticas econômicas entreguistas. Outra coisa é defender políticas econômicas elitistas.

A primeira lição que podemos extrair disso é que nacionalismo não necessariamente anda de mãos dadas com elitismo. Aliás, as elites aderem com frequência a ideias liberais e neoliberais que são o mais exato avesso do nacionalismo. É possível criticar a entrega de $60 \%$ do pré-sal a empresas estrangeiras em um contexto de defesa dos interesses econômicos das elites nacionais? Sim, é possível. Mas não parece ter sido essa a intenção de Safatle. É possível também criticar a entrega de $60 \%$ do pré-sal a empresas estrangeiras sem endossar nenhum tipo de elitismo? Sim, é possível. Aliás, tudo indica que não foi com nenhuma intenção elitista que ele criticou o entreguismo.

Outra lição que podemos extrair disso tudo é que existem pelo menos duas espécies de nacionalismo. A primeira é exemplificada pelo nacionalismo econômico que Safatle defendeu ao criticar a entrega de $60 \%$ do pré-sal a empresas estrangeiras. Não temos nada a objetar a essa espécie de nacionalismo. Também achamos o entreguismo absolutamente deplorável e 
escandaloso. Como se já não bastasse o passado colonial brasileiro e as privatizações que vêm de tempos em tempos lembrar que esse passado colonial ainda é muito presente, um governo supostamente não alinhado aos interesses do capital internacional decidiu entregar " $60 \%$ da maior reserva de petróleo da camada salina para quatro empresas estrangeiras". Quem quer que seja reprovado por simpatizar com o nacionalismo econômico safatliano poderá aproveitar a oportunidade para parafrasear chistosamente o famoso comentário de Papa Francisco: "Se me xingar de nacionalista econômico, espere um soco!". ${ }^{3}$ O problema não é ser denominado "nacionalista econômico", o problema é ser desqualificado como "nacionalista econômico". O problema é achar que aqueles que criticam o entreguismo são necessariamente provincianos. O problema é achar que aqueles que criticam o entreguismo são necessariamente elitistas. Em um país dilapidado como o Brasil, a designação "nacionalista econômico" não deveria ser vista como ofensa. Se não for possível usá-la como mera descrição, que pelo menos não seja usada como instrumento de difamação.

É claro que se as quatro empresas fossem, por exemplo, estatais haitianas, uma forma não negociável de nacionalismo econômico perderia um pouco de sua sedução. Porque agora a abertura de $60 \%$ do pré-sal para a exploração estrangeira não seria um ato de manutenção do violento jogo de forças internacionais que sacrifica década após década os países subalternos. Teria sido interessante, portanto, precisar de onde eram as referidas "empresas estrangeiras", o que Safatle não fez. Por quê? Provavelmente por saber quais são os países que nos vêm imediatamente à consciência (e sobretudo quais não nos vêm à consciência) quando nos referimos ao exterior de maneira não especificada. A importância desse detalhe aparentemente pequeno se torna flagrante quando consideramos que convergências superficiais às vezes ocultam divergências profundas. Por exemplo, duas pessoas com posicionamentos políticos radicalmente opostos podem ser igualmente contrárias à entrega de $60 \%$ do pré-sal a economias que já são grandes protagonistas no cenário internacional, porém uma insistindo que o pré-sal deve ser explorado única e exclusivamente pelo Brasil, e a outra se mostrando favorável à inclusão do pré-sal em acordos bilaterais com países latinoamericanos e africanos. No primeiro caso, podemos falar coerentemente em um resoluto, talvez excessivo, fechamento econômico; no segundo caso, não podemos falar que a abertura da exploração de $60 \%$ do pré-sal a "empresas estrangeiras" seria um grosseiro e deplorável ato de entreguismo. Deixando de lado o problema de determinar qual seria o posicionamento condizente com um governo de esquerda, e deixando de lado o problema deveras concreto de quais foram as tais "empresas estrangeiras", o que importa aqui é notar que duas posturas 
bastante diferentes frente aos atores econômicos internacionais podem se tornar indiscerníveis quando enunciadas por meio de máximas ou fórmulas gerais insaturadas.

Seria melhor que não existissem fronteiras nacionais, sem dúvida. Se o expansionismo europeu trouxe contribuições dignas do nome aos povos de todo o planeta, não consta entre elas a invenção de países. Mas enquanto existirem essas monstruosidades institucionais, conforme a expressão de Safatle, que os recursos naturais dos países periféricos sejam usufruídos primária e prioritariamente pelos países periféricos.

A segunda espécie de nacionalismo é aquela que Safatle atribuiu a Haddock-Lobo em seu artigo "Seria necessário algo como uma 'filosofia brasileira"?", publicado em fins de 2016 no site da Associação Nacional de Pós-Graduação em Filosofia (ANPOF). Safatle estava certo em atribuir a Haddock-Lobo um nacionalismo tão espúrio e elitista? Do nosso ponto de vista, que tentaremos defender nas páginas seguintes, Safatle foi longe demais ao ler em Haddock-Lobo o desejo de transpor para a filosofia acadêmica brasileira o projeto das "burguesias locais que procuravam, a partir do século XIX, justificar seu controle e suas fronteiras econômicas produzindo tradições, criando a ilusão de uma organicidade de ideias e formas que expressariam de maneira privilegiada o 'espírito' de um povo" (SAFATLE, 2016). Pois se quiséssemos falar seriamente dos interesses das elites brasileiras na fabricação da identidade nacional, teríamos que falar também da vergonha que ela sentia e ainda sente da população indígena e sobretudo da população negra, vergonha que se traduziu, por exemplo, nos programas de incentivo à imigração europeia. E teríamos que falar também da própria fundação da Universidade de São Paulo (USP) e da influência que ela exerceu e ainda exerce sobre os departamentos de filosofia de todo o Brasil. No primeiro caso, havia o desejo explícito de branquear o país. No segundo, o de afrancesá-lo intelectualmente:

Todos sabem que fomos formados na sólida tradição historiográfica francesa e que sua influência sobre nós foi extraordinariamente importante, particularmente sob a forma do assim chamado método estruturalista de leitura e estudo das obras filosóficas. (PORCHAT, 2010, p.19)

A vinda dos professores franceses para São Paulo, segundo testemunhos deles e dos que acompanharam suas aulas, foi um acontecimento de monta na cena cultural de então. (...) Assim, nesse agradável delírio, a distância que separa São Paulo de Paris estava como que suprimida, bem como um olhar crítico sobre a capital francesa. (SILVEIRA, 2015, pp. 204-5) 
A importância das missões francesas para a USP, notada inclusive por Foucault, já foi amplamente documentada (CRUZ COSTA, 1975; ARANTES, 1995; CARVALHO, 2012). As referências ao afrancesamento da filosofia acadêmica brasileira, porém, são quase sempre apologéticas e grosseiramente acríticas. A narrativa dominante é que os franceses salvaram a filosofia brasileira da barbárie. Um balanço menos heroico do legado das missões francesas, que traz à tona o que tem de mais embaraçoso, começou a ser feito apenas recentemente (ARMIJOS, 2004; PORCHAT, 2010; SEABRA, 2012; MARGUTTI, 2014; SILVEIRA, 2015; CANHADA, 2016).

É curioso notar que no texto de Haddock-Lobo não existe realmente nada do perigoso nacionalismo que Safatle leu nele; pelo contrário, o que existe é uma reflexão séria e saudável sobre a situação da filosofia acadêmica brasileira, uma reflexão atenta, comedida e ponderada, e até meio tímida, como se ele estivesse já pressentindo a reação negativa dos seus colegas de ofício. Por outro lado, há sinais muito claros de um desejo de afrancesamento na resposta de Safatle a Haddock-Lobo, de um desejo desinibido, quase declarado, de manter e proteger a orientação largamente eurocêntrica que impera nos departamentos de filosofia brasileiros. Dada a sua violenta represália à sugestão de Haddock-Lobo de que não precisamos nos curvar às diretrizes que se alastraram pelo Brasil por meio da USP, não é de todo implausível interpretar Safatle como se esforçando para proteger o legado das missões francesas.

Nas páginas seguintes, apontaremos algumas das falhas argumentativas mais gritantes presentes na crítica de Safatle a Haddock-Lobo. O fato de que Safatle, um dos intelectuais mais afiados do Brasil, mobilizou argumentos fracos e inconsistentes em sua investida contra a pergunta de Haddock-Lobo pela filosofia brasileira parece ser um forte sinal de que, retomando as palavras de Silveira, falta a ele "um olhar crítico sobre a capital francesa".

Onde está o perigoso nacionalismo de Haddock-Lobo? Em sua menção ao "processo colonial pelo qual também passou (e ainda passa) nossa academia" (HADDOCK-LOBO, 2016)? Mas ele defendeu em algum momento que devemos parar de ler filósofos europeus? E que devemos passar a ler única e exclusivamente autores brasileiros? Evidentemente, não há nada de radical, nada de insustentável, nada de excêntrico nas reflexões de Haddock-Lobo. De fato, a posição que ele defende é bastante razoável. Ela está muito bem expressa nas seguintes palavras: 


\begin{abstract}
Sem um olhar cuidadoso a essas experiências de pensamento, com a mesma dignidade filosófica que concedemos aos grandes pensadores europeus, nunca conseguiremos dar prosseguimento a uma necessária desconstrução do colonialismo que impera na filosofia. Enquanto não tratarmos os sistemas de pensamento iorubá, por exemplo, ou os ameríndios, como importantes elementos à especulação filosófica, nunca conseguiremos contribuir para que um dia possa vir a acontecer um pensamento de assinatura brasileira. (HADDOCK-LOBO, 2016)
\end{abstract}

Haddock-Lobo não nos pede para deixarmos de conceder dignidade filosófica "aos grandes pensadores europeus", apenas para passarmos a tratar com a mesma seriedade os sistemas de pensamento dos povos marginalizados pelo projeto modernizador brasileiro. Haddock-Lobo está sugerindo, por assim dizer, que cortemos o cordão umbilical que liga a filosofia acadêmica brasileira à Europa, o que não deve ser confundido com um projeto de solipsismo intelectual. A valorização da riqueza filosófica latente em solo nacional não implica necessariamente em xenofobia acadêmica.

Contudo, não parece ser isso o que Safatle teme? Seria totalmente infundada a hipótese de que Safatle teme que abrir espaço para as vozes mencionadas por Haddock-Lobo signifique abrir espaço para um provincialismo ingênuo e obtuso? Seria totalmente infundada a hipótese de que ele teme que todo o trabalho da missão civilizatória francesa seja perdido se levarmos as sugestões de Haddock-Lobo a sério? Parafraseando agora o próprio Safatle, temos "o direito de perguntar que medo é esse, o que ele, de fato, procura". ${ }^{4}$ Pois se ele tem o direito de bisbilhotar o inconsciente de Haddock-Lobo, ele automaticamente dá a todo mundo o direito de bisbilhotar o seu próprio inconsciente. Como o inconsciente é o lugar por excelência da orgia - o inconsciente é onde vale tudo -, quem entra nesse quarto escuro para examinar os outros precisa lembrar que pode também acabar sendo examinado.

Algumas perguntas talvez ajudem a tornar patente a estranheza da reação de Safatle às reflexões de Haddock-Lobo. Por acaso faz sentido ridicularizar os departamentos de letras brasileiros como nacionalistas pelo simples fato de incluírem autores nacionais em suas listas de leituras? O fato de que neles se lê autores nacionais significa que neles não se lê autores europeus? O fato de que neles se lê autores nacionais significa que são provincianos? E basta ler autores do norte atlântico para se deixar de ser provinciano? Quem lê exclusivamente autores de apenas quatro ou cinco países de uma porção territorialmente bastante circunscrita do planeta (França, Alemanha, Itália, Inglaterra e EUA), não está sendo necessariamente provinciano (ainda que seu provincianismo seja esquizoterritorializado)? E o que estaria motivando Haddock-Lobo a defender os interesses das elites brasileiras de fins do século XIX e princípios do XX, elites que já morreram e cujos descendentes, longe de estarem 
interessados em criar uma identidade nacional, envergonham-se dela e esforçam-se para dar ao Brasil feições metropolitanas e internacionalistas? $O$ que significa ver na crítica de Haddock-Lobo à nossa longa história de colonialismo epistêmico um passo em direção a um nacionalismo ultrapassado e burguês? Qual é o desejo de Safatle? Qual é o medo de Safatle?

Ao mencionar com orgulho a observação de Manfred Frank de que "alguém que procurasse estudar 'filosofia continental' deveria ir hoje não à Alemanha, mas à China ou ao Brasil”, Safatle reconhece em alta e clara voz que o problema da filosofia brasileira realmente não é de campo, o que torna bastante enigmática a afirmação, feita logo a seguir, de que a questão "da existência ou da necessidade de existência de uma 'filosofia brasileira' (...) simplesmente seja desprovida de sentido" e que ao contrário "devemos nos perguntar sobre as dificuldades de constituir um campo filosófico no Brasil" (SAFATLE, 2016). Safatle certamente sabe que a comunidade acadêmica de filosofia brasileira é hoje uma das maiores do mundo (CARVALHO, 2012). Por mais disfuncional e estranha que seja, trata-se claramente de uma maquinaria gigantesca. O problema da filosofia acadêmica brasileira não é de campo. Pelo contrário, o campo é a sua maior força. Talvez até a sua única força.

Transformando o que é realmente problemático em algo não problemático, e o que não é problemático em algo problemático, Safatle efetua um verdadeiro "jogo de inversões" (SAFATLE, 2016). Embora ele tenha acionado Manfred Frank para redirecionar a discussão de Haddock-Lobo para o problema do campo, não teria mais sentido acioná-lo para aprofundar e radicalizar a discussão de Haddock-Lobo? Pois não é curioso que o campo destroçado da filosofia alemã consiga ainda hoje produzir filósofos que possam ser desterritorializados e reclassificados como brasileiros, e que o campo da filosofia brasileira supostamente invejado por Manfred Frank não pareça estar em condições de produzir filósofos que possam ser desterritorializados e reclassificados como alemães? Markus Gabriel já conquistou espaço nas prateleiras de filosofia das livrarias de todo o país. Em breve aparecerão teses e dissertações a seu respeito, se ainda não apareceram. Mas dos milhares de propedeutas formados em massa ano após ano pelos departamentos de filosofia brasileiros, quantos estão sendo lidos na Alemanha? E que motivos teriam os alemães para lê-los?

Se um dia os filósofos alemães se interessarem por autores brasileiros, não será por propedeutas e sim pela espécie da qual os departamentos de filosofia brasileiro têm mais horror: os arrogantes e ingênuos aspirantes do mundo subdesenvolvido que querem pensar com as suas próprias forças. Trabalhar no desenvolvimento de ideias novas é uma 
prerrogativa das ex-metrópoles, não das ex-colônias. Como se diz frequentemente, não se pode filosofar ex nihilo.

Safatle tem razão em deplorar o nosso "regime de filiações" (SAFATLE, 2016). Mas o regime de filiações não é o único nem o mais importante problema da filosofia acadêmica brasileira. O problema da filosofia acadêmica brasileira, na verdade, é que ela mobiliza uma maquinaria gigantesca a serviço de objetivos muito pequenos. Desde a graduação até o pósdoutorado, o que se faz nos departamentos de filosofia brasileiros é essencialmente propedêutica. O que aparece nas revistas brasileiras de filosofia é essencialmente propedêutica. O que se faz nos congressos de filosofia brasileiros é essencialmente propedêutica. Portanto, o problema da filosofia acadêmica brasileira não é a carência de um campo robusto e racionalmente estruturado. O problema é que ela se convenceu - e se esforça constantemente para convencer as novas gerações - que fazer filosofia é essencialmente fazer propedêutica.

A propedêutica é o começo, o meio e o fím da filosofia acadêmica brasileira. Os filósofos acadêmicos brasileiros continuamente se policiam (a si mesmos e uns aos outros) para não saírem dos trilhos da propedêutica. Não é nenhuma surpresa, portanto, o fato de que estudantes do mundo todo possam agora vir para o Brasil ao invés de ir para a Alemanha a fim de estudar filosofia alemã. Só resta saber se isso deveria ser motivo de orgulho ou de vergonha. Talvez seja interessante contrabalancear o diagnóstico otimista de Manfred Frank acerca da comunidade brasileira de filosofia convidando Chico Science para participar da conversa: “A filosofia acadêmica brasileira não para, a filosofia acadêmica brasileira só cresce. O propedeuta sobe e o filósofo desce." ${ }^{5}$

A filosofia acadêmica brasileira respeita religiosamente a divisão internacional do trabalho intelectual. O papel dos países desenvolvidos é falar. O papel dos países em desenvolvimento é escutar. O papel dos países desenvolvidos é ensinar. O papel dos países em desenvolvimento é aprender. O papel dos países desenvolvidos é criar conceitos. O papel dos países em desenvolvimento é absorvê-los. O papel dos países desenvolvidos é civilizar. O papel dos países em desenvolvimento é abaixar a cabeça e agradecer. Haddock-Lobo parece, portanto, acertar em cheio ao defender a necessidade de uma "desconstrução do colonialismo que impera na filosofia" (HADDOCK-LOBO, 2016). E ao negar a pertinência das reflexões de Haddock-Lobo sobre o colonialismo epistêmico, Safatle parece estar se esforçando para manter o trem nos trilhos. 
Em sua crítica ao conceito de "assinatura" usado por Haddock-Lobo, conceito em torno do qual ele costura a sua pergunta pela filosofia brasileira, Safatle defende que "a não ser o fato de serem cidadãos do mesmo Estado-nação", talvez não exista "nada em comum, no sentido forte do termo, entre Alfred Whitehead e John Austin" (SAFATLE, 2016). Mas quem realmente acredita, além do próprio Safatle, que o grupo formado por Whitehead, Austin, Ryle e Strawson é mesmo tão heterogêneo quanto o grupo formado por Whitehead, Deleuze, Ryle e Lyotard? Quem realmente acredita que o grupo formado por Foucault, Deleuze, Guattari e Lyotard é mesmo tão heterogêneo quanto o grupo formado por Foucault, Austin, Guattari e Strawson? Como explicar as acusações dos analíticos de que os continentais são confusos? Como explicar as acusações dos continentais de que os analíticos são superficiais? Para piorar as coisas, o próprio Safatle já havia se referido explicitamente às "três grandes tradições da filosofia ocidental: a francesa, a anglo-saxônica e a alemã” (SAFATLE, 2007, p.8). Não há dúvida que Safatle é um bom esgrimista. Mas ao mudar de opinião sob medida para criticar Haddock-Lobo, ele cometeu um verdadeiro suicídio argumentativo. O ponto fica obviamente com Haddock-Lobo.

Talvez seja interessante notar que Safatle modera a sua investida dizendo que "boa parte do que chamamos de estilos nacionais talvez não se sustentem mais" (SAFATLE, 2016, s.p.), o que é bem diferente de dizer peremptoriamente "o que chamamos de estilos nacionais não se sustentam mais". Com as expressões "boa parte" e "talvez", ele não dá a entender que existem usos legítimos da noção de estilos nacionais? Não é que não faça sentido falar em estilos nacionais, é apenas que "boa parte" das vezes não faz sentido. Ou seja, Safatle está disposto a fazer concessões. Apenas não está disposto, ao que parece, a fazer concessões a Haddock-Lobo. Entre os usos do conceito de estilo nacional que se sustentam, não consta o uso feito por Haddock-Lobo. Assim duas perguntas ficam no ar. A primeira é: quais são os usos do conceito de estilo nacional que se sustentam?, e a segunda: por que o uso de Haddock-Lobo não consta entre eles? Apesar de Safatle dizer que não está, em sua argumentação contra Haddock-Lobo, aderindo a "um espírito gratuito de contenda", ele não explica, em nenhum momento, a razão pela qual está tão convencido de que o uso de Haddock-Lobo do conceito de estilo nacional não consta entre os seus usos legítimos. Ele explica porque "boa parte" dos usos do conceito é ilegítima. Mas não explica porque o uso de Haddock-Lobo cai nessa categoria. 
Safatle continua a sua desconstrução das reflexões de Haddock-Lobo evocando o caráter aparentemente errático e imprevisível dos "processos de recepção" de autores (SAFATLE, 2016). Pois se levarmos em conta a história da recepção de Heidegger, deveremos considerá-lo mais francês do que alemão. Mas não é estranho o fato de que Safatle se reporta em sua argumentação a exemplos insistentemente europeus (e masculinos)? Até mesmo o algeriano Derrida é reterritorializado da França para os Estados Unidos, sem mais nem menos. O que significa essa insistência? Como a sua curiosa desterritorialização é um ziguezague de nacionalidades que só sai da Europa para se aconchegar nos braços dos Estados Unidos, Safatle parece estar sinalizando que ele não se sente nem um pouco desconfortável com a geopolítica do saber da qual Haddock-Lobo quer se desvencilhar. Ele claramente toma como ilegítimas, impertinentes e irrelevantes as questões levantadas por Haddock-Lobo.

Mas que desterritorialização é essa que fica circunscrita a quatro ou cinco países, todos do norte atlântico? Pois ao invés de reclassificar Heidegger como francês, Safatle não poderia, para defender o mesmo ponto, tê-lo reclassificado como japonês? Aliás, dada a quantidade carnavalesca de propedêuticas a Heidegger escritas no Brasil, ele não poderia tê-lo reclassificado como brasileiro? Não poderia também tê-lo reclassificado como angolano? Ou como chinês? Ou como mexicano? Ou como indiano? E ao invés de usar um pensador europeu como exemplo (o que poderia ser mais previsível?), ele não poderia ter usado um pensador africano, asiático ou latino-americano? Ele não poderia ter reclassificado Vandana Shiva como alemã? Ele não poderia ter reclassificado Frantz Fanon como francês? Ele não poderia ter reclassificado Odera Oruka como norte-americano? Ele não poderia ter reclassificado Nishida Kitarō como britânico? Ele não poderia ter reclassificado Enrique Dussel como mexicano? Apesar da vastidão do mundo, Safatle se referiu apenas ao norte atlântico. Apesar da diversidade de pensadores que habitam o mundo, ele se referiu apenas a pensadores do norte atlântico. Mais uma vez, o ponto fica com Haddock-Lobo.

Talvez valha a pena citar aqui um pensador nigeriano que poderia ser facilmente desterritorializado para norte-americano, inglês, francês e alemão (mas dificilmente para brasileiro). Prestemos atenção às palavras com que Chinua Achebe abriu sua contribuição para uma conferência de acadêmicos britânicos e de ex-colônias britânicas realizada no ano de 1974 em Uganda: 
A palavra "colonialista" pode ser considerada inapropriada por duas razões. Primeiramente, ela acabou sendo associada, em muitas mentes, com aquela espécie de retórica barata, demagógica e atrasada que o famoso servidor público ganiano Robert Gardiner tinha, sem dúvida, em mente ao falar da nossa tendência a "entoar a litania colonial", querendo com isso dizer que chegou o momento de assumirmos responsabilidade por nossos problemas e por nossa situação no mundo, resistindo à tentação de culpar os outros. Em segundo lugar, pode ser dito que [existe agora] uma nova relação de igualdade entre povos que uma vez foram senhores e servos.

No entanto, apesar da força desses argumentos, sentimos a necessidade de lidar com algumas questões básicas levantadas por uma certa crítica especiosa que floresce hoje na literatura africana e que deriva da mesma suposição e postura básica do colonialismo, merecendo por isso o nome "colonialista". Essa suposição e postura se cristalizou no dictum imortal de Albert Schweitzer no auge do colonialismo: "O africano é de fato meu irmão, mas é meu irmão mais novo". Os críticos colonialistas mais recentes, igualmente inclinados à arrogância de irmão mais velho, veem os escritores africanos como europeus inacabados que, guiados com paciência, um dia crescerão para escrever como todos outros europeus, devendo, nesse ínterim, permanecer humildes, lendo tudo o que puderem, e dando o devido crédito aos seus professores na forma de elogios diretos, ou, o que seria ainda melhor, dado que elogios às vezes saem dos trilhos, tornando-se embaraçosos, na forma de autodesprezo. (ACHEBE, 1988, pp. 68-9)

Não mencionamos Achebe aqui simplesmente para contrabalancear a flagrante europeidade safatliana com um pouco de africanidade. Tampouco simplesmente para lembrar que o mundo, inclusive o mundo acadêmico, é bem maior do que imagina Safatle. O motivo pelo qual mencionamos Achebe é que ele sabe reequilibrar com uma dose necessária de respeito próprio a subserviência dos intelectuais dos países periféricos que esperam parecer teoricamente avançados criticando a "nossa tendência a entoar a 'litania colonial". Ele tem consciência das múltiplas faces que o autodesprezo pode assumir, das múltiplas formas pelas quais pode ser racionalizado. Ele sabe como é fácil, muito fácil, racionalizar o autodesprezo em discursos aparentemente esclarecidos. Assim, Achebe nos dá elementos para responder a pergunta que Fred Zero Quatro transformou em mantra: “É o ariano que ignora o africano ou é o africano que ignora o ariano?" (MUNDO LIVRE S/A, 1998; ver também SANCHES, 1998). De um lado, Haddock-Lobo parece lamentar que o ariano ignora o africano. Do outro, Safatle parece temer que o africano passe a ignorar o ariano. O que Achebe sugere é que precisamos rejeitar a disjunção para compreendermos verdadeiramente o que está acontecendo aqui: "É o ariano que ignora o africano, em parte porque o próprio africano ignora o africano.

É preciso pensar demorada e seriamente sobre a estratégia argumentativa usada por Safatle para criticar Haddock-Lobo. Pois ao deslegitimar a luta contra o colonialismo acadêmico rechaçando o conceito de identidade de forma indiscriminada e peremptória como se ele estivesse não apenas pressuposto por todo e qualquer gesto de recusa ao 
servilismo, mas sobretudo pressuposto em seus aspectos mais nefastos -, Safatle inadvertidamente deslegitima a luta contra o racismo. Apesar de ser possivelmente um mero efeito colateral da sua estratégia argumentativa, trata-se de um efeito suficientemente sério para merecer a nossa atenção.

O problema se dá porque Safatle não distingue entre uma noção forte, biológica, de identidade, denunciada habilmente pelos críticos do racismo, e uma noção fraca, simbólica, de identidade, forjada ao mesmo tempo para desalojar a primeira e para dar conta do fato de que referências a identidades raciais ocorrem frequentemente na esfera social. Não se pode pisotear a ideia de identidade impunemente, como se a sua versão fraca fosse indiscernível da sua versão forte. $\mathrm{O}$ esquema conceitual safatliano não é suficientemente versátil para lidar com o paradoxo de que embora não existam raças, os policiais sabem muito bem quem é negro e quem não é. $O$ fato de que raças são ficções culturais não significa que não exista racismo, muito menos que os críticos do racismo não tenham consciência de que raças são ficções culturais. Pelo contrário, a própria ideia de que raças são ficções culturais foi forjada pelos críticos do racismo. Se observarmos o quão pouco intuitiva é a noção fraca de identidade, compreenderemos adequadamente a magnitude dessa conquista teórica.

Mas o argumento de Safatle não se julga forte o suficiente para colocar em xeque toda e qualquer reflexão sobre questões que dizem respeito a identidades? Então por que deslegitimar apenas a luta contra os vetores raciais que estruturam a sociedade? Com efeito, seria possível parafraseá-lo para tentar calar também as nossas colegas feministas, argumentando que uma vez que o conceito de identidade de gênero é ultrapassado e perigoso (lembremos da observação safatliana carregada de veneno psicanalítico: "Tudo isso leva a uma pergunta: para que serve e a quem interessa insistir atualmente na existência de ‘filosofias nacionais'?” (SAFATLE, 2016), não existe, consequentemente, uma maneira coerente de formular nem as demandas práticas nem as análises teóricas que fizeram do feminismo um dos movimentos mais radicais e interessantes do século XX. Por que reclamar, por exemplo, do caráter predominantemente masculino da filosofia acadêmica? Afinal, se os filósofos são também lidos por mulheres, não podemos acionar os seus processos de recepção para desgenerizá-los e reclassificá-los como mulheres? Se Heidegger é francês por ser lido por franceses, então é mulher por ser lido por mulheres. E também negro por ter leitores de pele negra, e de esquerda por ter leitores de esquerda. Logo, podemos deixar de lado Angela Davis e Audre Lorde. Pois Heidegger dá conta do recado. 
A desterritorialização safatliana não foi levada ao "paroxismo" (SAFATLE, 2016). Ela simplesmente renovou, com todos os seus ziguezagues, o mesmo velho eurocentrismo colocado em questão por Haddock-Lobo. Com efeito, o que se pode concluir do embaralhamento territorial safatliano é algo bastante salutar para uma comunidade de propedeutas: exceto os filósofos brasileiros, todos os filósofos são brasileiros. Evidentemente, faz-se necessário manter em mente que o termo "todos" não é tão democrático quanto parece. Mas a aparência de universalidade precisa, sem dúvida, ser mantida. O que seria da Declaração Universal dos Direitos do Homem se ela fosse chamada de Declaração Universal dos Direitos do Homem Exceto dos Africanos? É precisamente essa uma das estratégicas clássicas o poder. É precisamente assim que o poder opera exclusões no plano discursivo: falando de forma universal e abstrata, mas aplicando as suas fórmulas de maneira enviesada.

De fato, Safatle apresenta aos propedeutas brasileiros uma solução simples a todos problemas trazidos por aqueles que insistem em trazer à tona as regras implícitas que governam as nossas práticas de produção e reprodução de saber. Uma vez que Heidegger é lido na África, na Ásia e na América Latina, podemos matar logo três coelhos com uma cajadada só e reclassificá-lo simultaneamente como africano (e parar de falar que o Brasil ignora a filosofia africana), asiático (e parar de falar que o Brasil ignora a filosofia asiática) e latino-americano (e parar de falar que o Brasil ignora a filosofia latino-americana). E como Heidegger é também negro e mulher, todas as críticas ao racismo e ao sexismo acadêmicos se tornam igualmente impertinentes.

O projeto de se fazer uma filosofia especificamente brasileira - uma filosofia que incorpore elementos do perspectivismo ameríndio, por exemplo - não está fadado inevitavelmente ao fracasso. Mas talvez seja mais interessante assumir pura e simplesmente a tarefa de nadar contra a correnteza da propedêutica e a sua produção em massa de literatura secundária que não interessa nem poderia interessar verdadeiramente a ninguém, sem que se defina de antemão o destino a que se quer chegar. Não é um desrespeito ao estudante obrigálo, depois de três ou quatro anos de estudos propedêuticos, a concluir o seu curso de graduação com mais um trabalho propedêutico? Não é desrespeitoso tornar a refreá-lo no mestrado e obrigá-lo de novo a escrever um trabalho propedêutico? Não é desrespeitoso repetir o mesmo no doutorado? Naturalmente, seria também desrespeitoso obrigá-lo a escrever uma filosofia verde e amarela. Os melhores trabalhos provêm do impulso interior de 
escrever, não de bandeiras e obrigações impostas de fora para dentro. É o impulso interior que gestaltiza, que dá organicidade, que torna prazeroso (e proveitoso) tanto o processo de escritura quanto o ulterior ato de leitura. As obrigações impostas de fora para dentro, ao contrário, produzem quebra de unidade e de fluidez. Assim como a regra da propedêutica degenerou em eurocentrismo, a regra da brasilidade poderia facilmente degenerar em ufanismo. Porque é da natureza das regras inibir o pensamento, como apontou Wittgenstein no prefácio das Investigações filosóficas para justificar a sua opção pelos aforismos. Precisamos de menos, não de mais regras. Se simplesmente abandonássemos essa regra que prescreve uma propedêutica eurocentrada e servil (e que proscreve tudo o que não seja uma propedêutica eurocentrada e servil), poderíamos talvez chegar a uma filosofia de feições brasileiras sem buscá-la explícita e deliberadamente.

Trata-se, de fato, não de apenas uma regra que inibe o livre fluir do pensamento, mas de uma massa de regras que policiam milimetricamente tanto a nossa agenda filosófica quanto o nosso estilo de escrita, tanto o nosso léxico quanto as nossas bibliografias, tanto os nossos métodos quanto a nossa posição enunciativa. As regras são tantas que somente a mais absoluta e rasteira mediocridade tem os seus direitos de cidadania garantidos. Não é à toa que a filosofia acadêmica brasileira está para a filosofia mais ou menos como a banda cover Os Besouros está para a música. Ao invés de apostar em uma fusão de gêneros, por exemplo, ela aposta em uma importação nua e crua do que se produz lá fora. E não se trata de um lá fora que se dispersa em todas as direções, não se trata de um lá fora que vai também para a América Latina, a África e a Ásia, mas de um lá fora que ao decolar do Brasil se dirige imediatamente ao norte atlântico.

Os membros da comunidade filosófica brasileira parecem achar que é mais seguro seguir os passos de Os Besouros do que os passos de Chico Science. No máximo, pode-se fazer algo como a banda paulista NX Zero, que, se não fossem por suas letras em português, poderia facilmente passar por uma banda de rock internacional (e mais uma vez, trata-se de um internacional localizadíssimo). E por que se pode seguir os passos de NX Zero? Porque, no fundo, NX Zero também é uma banda cover. Apenas não de conteúdos, mas de formas. Os Besouros copiam canções. NX Zero copia texturas sonoras. Chico Science, porém, comete o erro de não submeter as suas fontes de influência a uma triagem que obedeça ao ordenamento geopolítico internacional. Ele seria crucificado nas mãos da comunidade acadêmica de 
filosofia brasileira. Pelo simples fato de teimar em se manter aberto a influências locais, ele seria impiedosamente rechaçado como ufanista.

E de quem Os Besouros copiam suas canções? E de onde NX Zero copia suas texturas sonoras? Certamente, também as suas influências procedem de um lugar específico (aliás, muito específico). Mas não é verdade que não existem composições ex nihilo? E não é normal e saudável manter uma abertura a diferentes influências musicais? Acontece que a abertura a influências musicais das bandas Os Besouros e NX Zero é muito diferente da abertura a influências musicais de Chico Science. Nos primeiros dois casos, a paisagem sonora hegemônica não é de forma alguma ameaçada, sendo talvez mais apropriado falar aqui em abertura a influências geopolíticas do que em abertura a influências musicais. Pois nem uma banda nem outra recebe influências da música latino-americana. Nem uma banda nem outra recebe influências da música asiática. Nem uma banda nem outra recebe influências da música africana. A relação entre a filosofia acadêmica brasileira e as bandas Os Besouros e NX Zero, portanto, não é puramente metafórica. Existe entre elas uma relação de continuidade muito mais forte do que pode parecer à primeira vista. Os Besouros e NX Zero delimitam o espaço de manobra da filosofia acadêmica brasileira. E esse é o espaço da repetição, da identidade e (falando em bom português) da mesmice. Aqui não há lugar para Chico Science.

Não foi apenas na música brasileira que deu certo fazer coisas que não fossem nem Os Besouros nem NX Zero. Aliás, talvez seja interessante mencionar que Os Besouros e NX Zero deram errado justamente porque Chico Science deu certo. Algo semelhante ocorreu também na literatura, que incorporou o que era antes desclassificado como ruído e apostou corajosa e decisivamente na ampliação da matéria literária (SEABRA, 2012). O fato de que a literatura brasileira deu certo não significa que deu certo em todos os seus desdobramentos e manifestações, evidentemente. O fato de que ela deu certo não significa que deu certo nas mãos de todos aqueles que pararam de olhar para a Europa em busca de aprovação e aquiescência. Mas não há dúvida alguma de que deu certo.

Então por que algo semelhante não poderia dar certo na filosofia? Se referências a escritores e músicos europeus não contamina as nossas reflexões filosóficas (Safatle, por exemplo, menciona a música alemã do século XIX, sem causar em seus leitores a sensação de que falta ao seu pensamento seriedade), por que referências a escritores e músicos brasileiros e de outras partes do mundo necessariamente conduziriam ao ufanismo e à queda de 
qualidade? Por que não podemos mobilizar, ao escrever, todo o nosso acervo de experiências e referências culturais? Por que temos que submetê-las a uma triagem que deixa passar apenas aquelas que servem ao projeto de uma propedêutica eurocentrada? Consideramos o uso de Richard Wagner em nossas cadeias argumentativas como sinal de erudição. Por que não poderia também ser sinal de erudição usar Chico Science? Se parássemos de escalonar geopoliticamente a produção artística e intelectual do planeta, considerando todo o material cultural europeu como apropriável pela filosofia, mas não o material brasileiro, tomaríamos as referências a Chico Science como tão legítimas quanto as referências a Wagner. A lógica de fundo seguida pelos nossos propedeutas parece ser ao mesmo tempo elitista e eurocêntrica. Mencionar aquilo que só a elite intelectual brasileira conhece agrega valor intelectual aos seus escritos, tornando-os profundos e eruditos. Porém, mencionar aquilo que é de conhecimento mais geral dos brasileiros significa, ao contrário, ser rasteiro; significa abrir mão de todo e qualquer valor intelectual, incluindo, aliás, o valor estético. Mencionar elementos brasileiros é feio.

Samuel Rawet tem uma obra filosófica que começa de forma absolutamente genial:

Sou homem de crepúsculos. De transições. De nascimentos e mortes aparentes. E foi um crepúsculo vivido apaixonadamente que me deu o início deste livro. Já temi esta vibração. Hoje não temo a loucura. É uma forma de consciência-no-mundo que bem utilizada pode conduzir à abertura e ao conhecimento de espontaneidades esclerosadas pela tirania de covardes e hipócritas. Não temo a linguagem exaltada. O reino dos céus eu o tive há pouco. Tomo café na Praça Quinze, e compro cigarros. Discuto com o rapaz da caixa. Não tem a minha marca. Entro na barca das cinco. É noite ainda. Amanhece tarde neste junho de novecentos e setenta. Salto em Niterói. Sinto com prazer a flexibilidade de meus músculos enquanto caminho à procura, entre homens, de um outro café. Vício. Um deles. Vendedores de cintos e lâminas. Alguns ônibus descarregam gente apressada. Regresso com eles à barca. Regresso à Praça Quinze. Café. Caminho numa claridade tênue sobre as águas. Um desarranjo intestinal me leva a um bar da Assembleia. $O$ vaso está trancado à chave e a chave amarrada pelo português a uma barra de ferro. No instante exato consigo girá-la. Sentado penso na forma que devo dar a este trabalho. Escrevi os prolegômenos para uma teoria da consciência unificada em um trabalho considerado altamente pornográfico: devaneios de um solitário aprendiz da ironia. Para não me repetir mudo o tom. De novo na Assembleia, Rodrigo Silva, São José, Largo da Carioca. Dia. Há faixas de um sol ainda aquém do horizonte nas fachadas e nas nuvens. Ando pela Cinelândia deserta. Compro jornal. Raptaram o embaixador alemão. Clarice Lispector escreve sobre o infinito. (RAWET, 2008, p. 99)

Embora o texto não exiba do início ao fim a mesma verve, há certamente passagens que dão muito o que pensar. Por exemplo, a seguinte confissão rawetiana não pode deixar de 
ser mencionada: “Já caí no conto-do-vigário da erudição várias vezes” (RAWET, 2008, p.100). Outra passagem que poderia interessar aos estudantes de fenomenologia: "Quando a panela em que eu fervia a água para meu café tinha um furo lateral, a trajetória do fio líquido não consultava nenhuma sumidade para adquirir sua forma" (RAWET, 2008, p. 100). Algumas páginas adiante, reencontramos a desconfiança rawetiana contra o espírito do pensamento ocidental, que não é uma desconfiança contra o pensamento de forma geral: " $\mathrm{O}$ ocidental, bárbaro, ainda não conseguiu chegar ao nível do pensamento oriental. Ainda está fascinado pela erudição" (RAWET, 2008, p. 108). E também vemos uma observação sobre o efeito que pode ter sobre a consciência o fascínio da erudição livresca: "A consciência alienada, sim, tem leis (ela se escora em absolutos)" (RAWET, 2008, p. 108).

Ao nosso ver, porém, Rawet não desdobrou de forma suficientemente tenaz e sistemática as suas reflexões. Mas talvez o verdadeiro problema seja o fato de não lhe concedermos a generosidade propedêutica exigida pela leitura estrutural. Porque, afinal, ele repudia violentamente a ideia de sistema. Por exemplo, ele diz que: "A idiotice de qualquer sistematização é quase tão nefasta quanto a sistematização da idiotice" (RAWET, 2008, p.112). Seja como for, ele certamente entreviu um caminho interessante à sua frente e se colocou imediatamente a percorrê-lo. O projeto de Rawet não estava destinado ao fracasso logo de saída. O problema do projeto filosófico rawetiano vem não da sua concepção, não do seu desenho, mas do fato de que, como autor de múltiplos interesses, e talvez pressentindo o quanto o ambiente filosófico brasileiro era fechado em relação ao ambiente literário, ele não o levou adiante. Aliás, seria interessante tentar descobrir o motivo pelo qual ele se refere à "náusea de uma filosofia acadêmica, sistemática, fechada, eterna" (RAWET, 2008, p.120).

Aqui está certamente uma pista de como escapar do nosso atual servilismo intelectual. Rawet não tem vergonha de incorporar experiências e referências locais ao compor a sua visão do mundo. Assim como não faz sentido trocar uma obra-prima como "A La Ursa Quer Dinheiro", da esquecida banda pernambucana General Frank pelos inúmeros gritinhos de guitarra tecnicamente impecáveis, mas completamente pasteurizados, da badaladíssima e equalizadíssima NX Zero, também não faz sentido trocar as poucas páginas filosóficas que Rawet nos legou pelas milhares de propedêuticas produzidas em série todos os anos no Brasil. O servilismo tem que morrer. E deixar de ser servil não é simplesmente passar a ter uma relação menos submissa e mais crítica com a tradição europeia. Pelo contrário, deixar de ser servil é algo muito mais radical: 


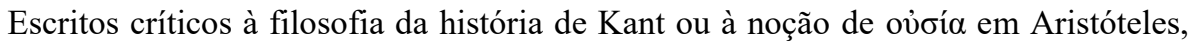
que são certamente publicados com frequência na academia, poderiam causar a falsa impressão de que, por existirem, negam a atitude celebratória que estamos denunciando. Acontece que essa atividade crítica, a despeito do enorme interesse e profundidade que pode ter em outros termos, se dá geralmente sem colocar em questão a própria postura com que nos relacionamos com obras filosóficas, postura em que todo o material do pensar tem de estar referenciado à história canônica da filosofia europeia. (...) Quando apreendemos a situação da formação em filosofia nos termos que propusemos, temos de chegar a seguinte conclusão: admirar excessivamente os clássicos da filosofia é uma irresponsabilidade. (SILVEIRA, 2015, p. 218)

Deixar de ser servil é escapar não apenas do regime de filiações do qual Safatle fala, mas sobretudo do regime de filiações do qual ele não fala. Deixar de ser servil é deixar de lado, nas palavras de Silveira, essa "atitude celebratória" segundo a qual "todo o material do pensar tem de estar referenciado à história canônica da filosofia europeia”. Deixar de ser servil é deixar de usar Hegel para criticar Kant, Marx para criticar Hegel, Foucault para criticar Marx ad infinitum e ad nauseam. Deixar de ser servil é deixar de usar a filosofia continental para criticar a filosofia analítica e a filosofia analítica para criticar a filosofia continental. Deixar de ser servil é deixar de achar e sobretudo de sentir como problemático citar Chico Science, mas não citar Wagner. Deixar de ser servil é deixar de abaixar a cabeça para a etiqueta visceralmente elitista que controla as nossas referências bibliográficas, pedindo-nos para manter um regime de leituras endodérmico e para citar apenas o que é publicado no circuito editorial oficial. Deixar de ser servil é deixar de seguir obedientemente as bizarras e humilhantes regras implícitas dos departamentos de filosofia brasileiros que ninguém tem coragem de enunciar com todas as letras. Deixar de ser servil é deixar de identificar anticolonialismo a ufanismo. Deixar de ser servil é deixar de identificar seriedade a europeidade. Deixar de ser servil é deixar de submeter o pensamento a um processo de assepsia que consiste em tirar dele tudo o que é local em benefício de tudo o que é internacional (e de um internacional bem mais local do que geralmente se reconhece).

Parece que Safatle não se incomoda nem um pouco em ilustrar (especialmente com a sua desterritorialização superterrorializada) o fato de que para a filosofia acadêmica brasileira a Europa traça e circunscreve os limites da imaginação teórica. Ela é a fonte de todas as nossas metáforas e exemplos. Ela é a fonte de todos os nossos dados e argumentos. Ela é a referência última a que recorremos para determinar se aquilo que estamos fazendo é certo ou errado. Ela é a lei máxima evocada para legitimar e deslegitimar as nossas aventuras especulativas. Ela é a placenta que precisamos para respirar. Ela é a autoridade paterna que protegemos do parricídio. Fornecendo o próprio vocabulário das nossas reflexões, a Europa é 
o começo e o fim de toda a nossa propedêutica que trabalha dia e noite para se fazer passar por filosofia.

Podemos ser facilmente levados a resolver a diferença entre Haddock-Lobo e Safatle como consistindo no fato de que o primeiro lança mão de um arcabouço teórico atrasado e reacionário (para articular um discurso de direita, o que torna a sua posição ainda mais indefensável) e o segundo de um arcabouço teórico atualizado e sofisticado (para articular um discurso de esquerda, o que torna a sua posição ainda mais louvável). De fato, Safatle parece interpretar a fraqueza dos objetivos e temas de Haddock-Lobo sob a chave geográfica, e a fraqueza dos seus conceitos e instrumentos de análise sob a chave histórica. Enquanto o primeiro liberta o pensamento por meio de ferramentas conceituais francesas do século $\mathrm{XX}, \mathrm{o}$ segundo aprisiona o pensamento a ferramentas conceituais alemãs do século XIX. Safatle fundamenta o seu antinacionalismo em ideias antiessencialistas, e acusa Haddock-Lobo de fundamentar o seu nacionalismo em ideias essencialistas.

No entanto, as coisas são um pouco mais complexas. Safatle pinta Haddock-Lobo como se, ignorando a filosofia francesa contemporânea, ele incorresse no erro de recuperar um essencialismo perigoso e ingênuo. A verdade, porém, é que ele se mostra perfeitamente consciente da filosofia francesa que Safatle aciona para atacá-lo. De fato, ele a utiliza em sua argumentação com a mais absoluta naturalidade, como se ela já estivesse profundamente sedimentada em seu ser. Para Haddock-Lobo, ela não é tópico de discussão e sim reserva teórica. Por exemplo, ao dizer que o Movimento Antropofágico pode ser entendido como "a primeira tentativa de desenhar uma assinatura de pensamento 'brasileira", ele acrescenta que a ideia de brasilidade não se refere a "algo de 'próprio', 'idêntico"” e sim a uma "multiplicidade"; e, logo em seguida, afastando-se do mito das três raças que teriam formado o Brasil, ele se refere às identidades negra e ameríndia como criadas "por oposição" à identidade europeia (HADDOCK-LOBO, 2016). É de se perguntar, naturalmente, porque ele coloca "negro" e "ameríndio" entre aspas, porém não "europeu", pois a identidade europeia é uma construção tão fantasiosa quanto as identidades negra e ameríndia. Mas o que importa notar aqui é que não há absolutamente nada de essencialista nem na ideia de identidades sem algo de próprio nem na ideia de identidades construídas por oposição. Se a volatilização das identidades constitui uma marca da filosofia francesa contemporânea, Haddock-Lobo não deixa nada a desejar em relação a Safatle. No que diz respeito ao conhecimento da matéria 
obrigatória, os dois estão igualmente em dia. Safatle está claramente equivocado ao supor que Haddock-Lobo não fez o dever de casa.

Para marcar e defender posições diametralmente opostas, Haddock-Lobo e Safatle utilizam instrumentos conceituais que compartilham uma mesma e única origem: as forjas filosóficas europeias. Do ponto de vista de suas filiações teóricas, portanto, a grande diferença entre Haddock-Lobo e Safatle não é nem temporal nem espacial: um está tão atualizado quanto o outro, e um é tão europeu quanto o outro. A grande diferença entre eles está não nos conceitos de que se servem, mas no uso que fazem dos conceitos de que se servem. Uma coisa é usar as técnicas militares espanholas ao estilo Gonzalo Guerrero. Outra coisa é usá-las ao estilo Hernán Cortés. As mesmas ferramentas - inclusive as mesmas ferramentas conceituais - podem ser e frequentemente são mobilizadas com propósitos muito distintos. HaddockLobo utiliza a filosofia europeia para criticar a sua hegemonia. Safatle utiliza a filosofia europeia para restabelecer a sua hegemonia. Não podemos acusar Safatle de falta de coerência. Mas o ponto, mais uma vez, fica com Haddock-Lobo.

Safatle deveria ter atravessado e não fechado a porta aberta por Haddock-Lobo. Afinal, não há nada demais no que Haddock-Lobo propõe. O que ele sugere não é apenas realizável, como também desejável. Alguém realmente acredita que não devemos ampliar o nosso leque de leituras e diversificar as nossas referências bibliográficas? Alguém realmente acha recomendável ler menos ao invés de ler mais? O que Haddock-Lobo está dizendo é muito simples: podemos alimentar os nossos motores reflexivos com conceitos das mais diversas proveniências e destiná-los à análise dos mais diversos temas. Não percamos a oportunidade de usufruir do material à nossa volta.

É uma falta de respeito próprio tomar Os Besouros e NX Zero como delimitando o espaço de manobra de tudo o que se pode fazer em filosofia, especialmente quando se sabe muito bem que não reproduzir conteúdos de forma explícita não basta para sair da condição de banda cover. As reflexões de Haddock-Lobo tornam-se mais do que pertinentes quando vemos uma das maiores comunidades de filosofia do planeta dando as costas para o meio em que se insere e canalizando os seus esforços única e exclusivamente para tocar músicas cover ao estilo Os Besouros ou rock internacional ao estilo NX Zero. O ponto fundamental não é que existe uma diferença, talvez negligenciável, talvez não negligenciável, entre essas duas bandas. O ponto fundamental é que existe uma diferença qualitativa inegável entre essas duas bandas e Chico Science. E não se trata de uma diferença qualitativa apenas no sentido de que 
Chico Science é melhor, mas, sobretudo, no sentido de que Chico Science faz músicas de uma espécie muito diferente. É perfeitamente razoável esperar que haja também uma diferença qualitativa inegável entre os escritos de quem se apega a fórmulas prontas e os escritos de quem se dispõe a pensar com as próprias forças. ${ }^{6}$

\section{NOTAS}

\footnotetext{
${ }^{1}$ Doutorando em Antropologia pela La Trobe University, Austrália. E-mail: murilorseabra@gmail.com.

${ }^{2}$ Doutora em Discourse Analysis, University of Queensland, Austrália. Lecturer, La Trobe University, Austrália. E-mail: 1.tolton@latrobe.edu.au.

${ }^{3} \mathrm{~A}$ frase original é "Perché è vero che non si può reagire violentemente. Ma se il dottor Gasbarri, che è un amico, dice una parolaccia contro mia mamma, si aspetta un pugno" (ver ANSALDO, 2015).

${ }^{4}$ A frase original é "Esta questão expressa um desejo, mas talvez tenhamos o direito de se (sic) perguntar que desejo é este, o que ele, de fato, procura" (SAFATLE, 2016).

${ }^{5} \mathrm{O}$ verso original é "A cidade não para, a cidade só cresce, o de cima sobe, o de baixo desce" (CHICO SCIENCE \& NAÇÃO ZUMBI, 1994).

${ }^{6}$ Uma versão resumida do presente artigo foi enviada por Murilo Seabra para a Coluna ANPOF. Porém, a diretoria da ANPOF se recusou a publicá-lo. A alegacão foi que somente artigos de autores convidados eram publicados. Para testar a explicação oferecida pela ANPOF, Murilo Seabra escreveu para seis autores que haviam publicado na Coluna ANPOF perguntando se eles efetivamente tinham sido convidados. Dois responderam afirmativamente: eles haviam, sim, sido convidados. Mas quatro responderam negativamente: eles não haviam sido convidados. Quando a ANPOF foi novamente interpelada sobre o assunto, ela se recusou a dar explicações.
}

\section{REFERÊNCIAS BIBLIOGRÁFICAS}

ACHEBE, C. "Colonialist Criticism". In: Hopes and Impediments: Selected Essays. New York: Anchor, 1988.

ANSALDO, M. "Francesco: 'Si aspetti un pugno chi offende mia madre. La libertà di parola ha dei limiti"”. In: La Repubblica, 16.01.2015. Acessado em 25 jan. 2017: $<$ http://www.repubblica.it/esteri/2015/01/16/news/francesco_si_aspetti_un_pugno_chi_offend e_mia_madre_la_libert_di_parola_ha_dei_limiti-105051331>.

ARANTES, P. "Uma História dos Paulistas no seu Desejo de ter uma Filosofia. Duas entrevistas com Paulo Arantes”. In: Revista Trans/Form/Ação, No. 18, 1995, pp. 183-198.

ARMIJOS, G. De como fazer Filosofia sem ser Grego, estar Morto ou ser Gênio. Goiânia: Ed. UFG, 2004.

CANHADA, J. "La Lecture Structurale des Textes et l'Histoire de la Philosophie au Brésil". In: Cahiers Critiques de Philosophie, No. 16, août-septembre, 2016, pp. 87-105.

CARVALHO, M. "Passé et Présent de la Philosophie au Brésil". In: Rue Descartes, No. 76/4, 2012, pp. 126-136

CHICO SCIENCE \& NAÇÃO ZUMBI. “A Cidade”. In: Da Lama ao Caos. Rio de Janeiro: Chaos, 1994. 
CRUZ COSTA, J. "Sobre o Trabalho Teórico: Entrevista com João Cruz Costa". In: Revista Trans/Form/Ação, Vol. 2, 1975, pp. 87-94.

MARGUTTI, P. "Sobre a nossa Tradição Exegética e a Necessidade de uma Reavaliação do Ensino de Filosofia no País”. In: Kriterion, No. 129, jun. 2014, pp. 397-410.

MUNDO LIVRE S/A. "O Africano e o Ariano". In: Carnaval na Obra. São Paulo: Abril Music, 1998.

PORCHAT, O. "Discurso aos Estudantes de Filosofia da USP sobre a Pesquisa em Filosofia". In: Fundamento, Vol. 1, No. 1, set./dez. 2010, pp. 18-33.

RAWET, S. Ensaios Reunidos. Rio de Janeiro: Civilização Brasileira, 2008.

SEABRA, M. "História da Arte e das Ciências Humanas: Palcos para Lutas Linguísticas". In: Áskesis: Revista dos Discentes do PPGS/UFSCar, Vol. 1, No. 2, jul./dez. 2012, pp. 124-139.

SILVEIRA, G. "A Modernização do Pensar como Violência: O Legado das Missões Francesas da USP e o Caso Jean Maugüé”. In: Problemata: Revista Internacional de Filosofia. No. Especial, 2015, pp. 202-221.

HADDOCK-LOBO, R. “Filosofia brasileira - uma questão?”. In: Coluna Anpof, 05.10.2016. Acessado em 25 jan. 2017: <http://anpof.org/portal/index.php/pt-BR/comunidade/colunaanpof/848-filosofia-brasileira-uma-questao $>$.

SAFATLE, V. “Grande Hotel Abgrund”. In: O que nos faz pensar, Vol. 1, No. 22, dez. 2007, pp. 7-22.

SAFATLE, V. “Seria necessário algo como uma 'filosofia brasileira'?”. In: Coluna Anpof, 19.10.2016. Acessado em 25 jan. 2017: http://anpof.org/portal/index.php/ptBR/comunidade/coluna-anpof/921-seria-necessario-algo-como-uma-filosofia-brasileira.

SAFATLE, V. “O que realmente entrou em crise?”. In: Folha de São Paulo, 06.11.2015. Acessado em 25 jan. 2017:

$<$ http://www1.folha.uol.com.br/colunas/vladimirsafatle/2015/11/1702707-o-que-realmenteentrou-em-crise.shtml>.

SANCHES, P. "Mundo Livre Chega Atacando "Arianos"”. In: Folha de São Paulo, 26.08.1998. Acessado em 25 jan. 2017:

$<$ http://www1.folha.uol.com.br/fsp/ilustrad/fq26089819.htm>. 